\title{
Aerobic exercises alleviate symptoms of fatigue related to inflammatory cytokines in obese patients with type 2 diabetes.
}

\author{
Shehab M. Abd El-Kader ${ }^{1}$, Osama H. Al-Jiffri' ${ }^{2}$, Fadwa M. Al-Shreef ${ }^{2}$
}

1. Department of Physical Therapy, Faculty of Applied Medical Sciences, King Abdulaziz University.

2. Department of Medical Laboratory Technology, Faculty of Applied Medical Sciences, King Abdulaziz University.

\begin{abstract}
Background: Non-insulin dependent diabetic patients frequently suffer from fatigue symptoms that result from chronic systemic inflammation. Aerobic exercise was proved to modulate systemic inflammation.

Objective: This study was an attempt to measure the impact of aerobic exercises on fatigue symptoms related to systemic inflammation in obese patients with type 2 diabetes.

Methods: Eighty obese patients with type 2 diabetes participated in the present study, their age ranged from 40- 58 years and their BMI ranged from $31-36 \mathrm{~kg} / \mathrm{m}^{2}$ and were assigned to two subgroups; group (A) received aerobic exercise training for 12 weeks and group (B) received no exercise training for 3 months. Measurements of fatigue symptoms and markers of systemic inflammation were assessed before and at the end of the study for all participants in both groups.

Results: The mean values of inflammatory markers (IL-6 and TNF- $\alpha$ ) and Multidimensional Fatigue Inventory (MFI) was significantly decreased in group (A), while changes were not significant in group (B). Moreover, there were significant differences between mean levels of the investigated parameters in group (A) and group (B) at the end of the study.

Conclusion: Treadmill walking exercise training is an effective treatment policy to improve symptoms of fatigue related to inflammatory cytokines in obese patients with type 2 diabetes.

Keywords: Aerobic exercise, inflammatory cytokines, obesity, Type 2 diabetes, fatigue syndrome.

DOI: http://dx.doi.org/10.4314/ahs.v15i4.13

Cite as: Abd El-Kader SM, Al-Jiffri OH, Al-Shreef FM. Aerobic exercises alleviate symptoms of fatigue related to inflammatory cytokines in obese patients with type 2 diabetes. Afri Health Sci. 2015;15(4):1142-8. http://dx.doi.org/10.4314/abs.v15i4.13
\end{abstract}

\section{Introduction}

Patients with type 2 diabetes commonly experience fatigue, which may be incapacitating and adversely affect self-care regimens ${ }^{1}$ which increases the risk of other diabetic complication along with its adverse affection on diabetic patient quality of life ${ }^{2,3}$. Most people with insulin-resistant type 2 diabetes are either overweight or obese $^{4}$. Increased levels of pro-inflammatory cytokines (as seen in obese individuals) may be significant factors in fatigue levels ${ }^{5}$. Fatigue is a perplexing problem for healthcare providers as fatigue is challenging to diagnose and treat. Fatigue in patients with type 2 diabetes

\section{Corresponding author: \\ Shehab M. Abd El-Kader, \\ Department of Physical Therapy, \\ Faculty of Applied Medical Sciences, \\ King Abdulaziz University, \\ P.O. Box 80324, Jeddah, 21589,Saudi Arabia. \\ E. mail: salmuzain@kau.edu.sa}

may be is associated with higher body mass index (BMI) and elevated cytokines ${ }^{6}$.

Increased levels of circulating inflammatory markers were found to be significantly more prominent in patients with type 2 diabetes ${ }^{7-10}$. Systemic inflammation in type 2 diabetes is believed to originate, at least partially, from the adipose tissue ${ }^{11-14}$. The ability of pro-inflammatory cytokines (e.g., interleukin - 6 (IL-6), tumor necrosis factor-alpha (TNF)- $\alpha$ ) to act on the brain and to induce behavioral symptoms, including fatigue, is well documented in both experimental and clinical studies ${ }^{15}$. However; aerobic exercises inhibit the production of inflammatory cytokines ${ }^{16}$.

Data from observational studies suggest that low levels of physical activity are associated with higher levels of fatigue in patients with type 2 diabetes ${ }^{16}$. The general benefits of aerobic exercise training are well proved ${ }^{17}$ and the cancer patients had less fatigue perception with increasing activities ${ }^{18}$. Much evidence supports the pos- 
itive effects of regular physical activity on alleviating symptoms of fatigue ${ }^{19,20}$.

There is a considerable gap in the literature, however, about the treatment of fatigue secondary to type 2 diabetes. Anti-inflammatory therapies may ameliorate fatigue with type 2 diabetes. While there have been no clinical trials of the effects of an exercise intervention on fatigue symptoms in type 2 diabetes, results from exercise trials in both healthy and diverse disease populations have shown that regular exercise may be an effective strategy for decreasing fatigue. Thus, our study was an attempt to assess the effects of aerobic exercise upon fatigue symptoms associated with markers of systemic inflammation in obese patients with type 2 diabetes.

\section{Patients and methods \\ Subjects}

Eighty obese patients with type 2 diabetes were enrolled in this study; their age ranged from 40- 58 years and their BMI ranged from $31-36 \mathrm{~kg} / \mathrm{m}^{2}$ and were selected from the Internal Medicine Department at King Abdul Aziz University hospital and other hospitals at Jeddah area. Exclusion criteria included major depressive disorder, endocrine disorders, smokers, chronic inflammatory medical conditions, patients managed with psychiatric medications. Participants were included two groups; group (A) received treadmill aerobic exercise training on treadmill and group (B) received no exercise training. All participants signed the informed consent.

\section{Measurements}

A. Anti-inflammatory cytokines assessment: Venous blood samples were drained from the antecubital vein after a 12 -h fasting, the blood samples were centrifuged at $+4{ }^{\circ} \mathrm{C}(1000=\mathrm{g}$ for $10 \mathrm{~min})$. Interleukin -6 levels were analyzed by "Immulite 2000" immunassay analyzer (Siemens Healthcare Diagnostics, Deerfield, USA). However, TNF- $\alpha$ and interleukin-8 (IL-8) levels were assessed by ELISA kits (ELX 50) in addition to ELISA microplate reader (ELX 808; BioTek Instruments, USA). All analyses were done by Hitachi 7170 Autoanalyser (Tokyo, Japan) and kits (Randox).

B. Fatigue Assessment: Fatigue was measured by completion of the Multidimensional Fatigue Invento- ry (MFI). The MFI was used to capture five distinct dimensions of fatigue experienced "lately", including: general fatigue, physical fatigue, mental fatigue, and perceptions of reduced motivation and reduced activity. In each of the five subscales, scores range from 4 to 20 , with higher scores indicating greater fatigue. In order to minimize confounding factors imposed by diurnal variation, this questionnaire was completed on the morning of the blood draw. Internal consistency for the MFI subscales was good $(a=0.82)$, suggesting the five domains adequately reflect a single construct ${ }^{21}$.

All measurements of TNF- $\alpha$, Il-6, IL- 8 and MFI were done at the beginning of the study and repeated after 3 months at the end of the study.

\section{Procedures}

Following the previous evaluation, all patients were divided randomly into the following groups:

1. Group (A) participated in a treadmill aerobic exercise which was conducted according to recommendations of aerobic exercise application approved by the American College of Sports Medicine ${ }^{22}$.Training program included 5 minutes for warming up in the form of range motion and stretching exercises, 10-30 minutes of aerobic exercise training (60-70\% of maximum heart rate) and 10 minutes of cooling down (on treadmill with low speed and without inclination). Participants had 3 sessions / week for 3 months with close supervision of a physical therapist.

2. Group (B) received no exercise training.

\section{Statistical analysis}

The mean values of the investigated parameters obtained before and after three months in both groups were compared using paired " $t$ " test. Independent " $t$ " test was used for the comparison between the two groups $(\mathrm{P}<0.05)$.

\section{Results}

Eighty obese patients with type 2 diabetes (44 men and 36 women) were enrolled in this study, there were no significant differences in age, body mass index, hip circumference, waist circumference, waist hip ratio, $\mathrm{HbA1C}$, diabetes duration, systolic blood pressure and diastolic blood pressure between both groups (table 1). 
Table 1: Demographic and anthropometric characteristics of study participants.

\begin{tabular}{|l|c|c|c|}
\hline & Group (A) & Group (B) & Significance \\
\hline Sample size (N) & 40 & 40 & $\mathrm{P}>0.05$ \\
\hline Age (year) & $43.62 \pm 6.17$ & $44.11 \pm 5.89$ & $\mathrm{P}>0.05$ \\
\hline Gender (F/M) & $19 / 20$ & $17 / 22$ & $\mathrm{P}>0.05$ \\
\hline BMI (kg/m2) & $31.65 \pm 5.53$ & $30.87 \pm 5.76$ & $\mathrm{P}>0.05$ \\
\hline HC $(\mathrm{cm})$ & 123.4813 .17 & 121.7911 .62 & $\mathrm{P}>0.05$ \\
\hline WC (cm) & 107.1110 .56 & 106.5412 .13 & $\mathrm{P}>0.05$ \\
\hline WHR & 0.950 .07 & 0.920 .07 & $\mathrm{P}>0.05$ \\
\hline HbA1C (\%) & 8.941 .85 & 8.571 .47 & $\mathrm{P}>0.05$ \\
\hline Diabetes duration (year) & 11.422 .16 & 10.831 .97 & $\mathrm{P}>0.05$ \\
\hline SBP(mmHg) & 144.1216 .18 & 142.7614 .34 & $\mathrm{P}>0.05$ \\
\hline DBP (mmHg) & 93.327 .31 & 92.228 .13 & $\mathrm{P}>0.05$ \\
\hline
\end{tabular}

BMI: Body Mass Index; HC: Hip circumference; WC: Waist circumference; WHR: Waist hip ratio HbA1C: Glycosylated haemoglobin; SBP: Systolic blood pressure; DBP: Diastolic blood pressure.

There were $28.5 \%, 26.2 \%, 15.1 \%, 8 \%$ and $25.4 \%$ MFI total score respectively in the training group (table reduction in mean values of TNF- $\alpha$, IL-6, IL-8, BMI, 2).

Table 2: Values of TNF- $\alpha$, IL-6, IL-8, MFI total score and fatigue symptom dimensions in group (A) before and after treatment.

\begin{tabular}{|l|c|c|c|c|}
\hline \multirow{2}{*}{} & \multicolumn{2}{|c|}{ Mean + SD } & \multirow{2}{*}{$\begin{array}{c}\text { t- } \\
\text { value }\end{array}$} & Significance \\
\cline { 2 - 4 } & $\begin{array}{c}\text { Before } \\
\text { treatment }\end{array}$ & $\begin{array}{c}\text { After } \\
\text { treatment }\end{array}$ & & \\
\hline TNF- $\boldsymbol{\alpha}(\mathrm{pg} / \mathrm{mL})$ & $6.15 \pm 1.63^{*}$ & $4.37 \pm 1.48$ & 6.82 & $\mathrm{P}<0.05$ \\
\hline IL-6 $(\mathrm{pg} / \mathrm{mL})$ & $6.83 \pm 2.15^{*}$ & $5.04 \pm 1.92$ & 5.87 & $\mathrm{P}<0.05$ \\
\hline IL-8 $(\mathrm{pg} / \mathrm{mL})$ & $14.17 \pm 3.93^{*}$ & $12.03 \pm 3.61$ & 7.93 & $\mathrm{P}<0.05$ \\
\hline BMI $\left(\mathrm{kg} / \mathrm{m}^{2}\right)$ & $31.65 \pm 5.53^{*}$ & $26.82 \pm 4.88$ & 7.58 & $\mathrm{P}<0.05$ \\
\hline MFI total score & $55.12 \pm 12.94^{*}$ & $41.11 \pm 13.72$ & 6.54 & $\mathrm{P}<0.05$ \\
\hline Fatigue symptom dimensions & \multicolumn{2}{|c}{} \\
\hline General fatigue & $13.28 \pm 2.85^{*}$ & $9.52 \pm 3.61$ & 5.43 & $\mathrm{P}<0.05$ \\
\hline Physical fatigue & $12.17 \pm 3.16^{*}$ & $8.74 \pm 2.92$ & 6.76 & $\mathrm{P}<0.05$ \\
\hline Reduced activity & $11.33 \pm 3.62^{*}$ & $8.15 \pm 3.43$ & 5.81 & $\mathrm{P}<0.05$ \\
\hline Mental fatigue & $9.11 \pm 3.72^{*}$ & $7.54 \pm 3.24$ & 6.74 & $\mathrm{P}<0.05$ \\
\hline $\begin{array}{l}\text { Reduced } \\
\text { motivation }\end{array}$ & $9.23 \pm 2.32^{*}$ & $7.16 \pm 3.41$ & 5.36 & $\mathrm{P}<0.05$ \\
\hline
\end{tabular}

TNF- $\alpha$ : tumor necrosis factor - alpha; IL-6: Interleukin-6; BMI: Body Mass Index; IL-8: Interleukin-8;

MFI: Multidimensional Fatigue Inventory; $\left(^{*}\right)$ indicates a significant difference between the two groups, $\mathrm{P}<0.05$.

While, there were $2.1 \%, 2.3 \%, 0.42 \%, 2.2 \%$ and 2.1 $\%$ increase in mean values of TNF- $\alpha$, IL- 6 , IL- 8, BMI, MFI total score respectively in the control group. The mean values of TNF- $\alpha$, IL-6, IL-8, BMI, MFI total score were decreased significantly in the training group; however the results of the control group were not significant (table 3). 
Table 3: Values of TNF- $\alpha$, IL-6, IL-8, MFI total score and fatigue symptom dimensions in group (B) before and at the end of the study.

\begin{tabular}{|c|c|c|c|c|}
\hline & \multicolumn{2}{|c|}{ Mean + SD } & \multirow[b]{2}{*}{$\begin{array}{c}\mathrm{t}- \\
\text { value }\end{array}$} & \multirow[b]{2}{*}{ Significance } \\
\hline & $\begin{array}{l}\text { Before the } \\
\text { study }\end{array}$ & $\begin{array}{l}\text { At the end of } \\
\text { the study }\end{array}$ & & \\
\hline TNF- $\boldsymbol{\alpha}(\mathrm{pg} / \mathrm{mL})$ & $5.98 \pm 1.47$ & $6.11 \pm 1.42$ & 0.87 & $\mathrm{P}>0.05$ \\
\hline IL-6 (pg/mL) & $6.42 \pm 2.21$ & $6.57 \pm 2.18$ & 0.63 & $\mathrm{P}>0.05$ \\
\hline IL-8 (pg/mL) & $14.31 \pm 3.75$ & $14.25 \pm 3.70$ & 0.41 & $\mathrm{P}>0.05$ \\
\hline BMI $\left(\mathrm{kg} / \mathrm{m}^{2}\right)$ & $31.14 \pm 5.17$ & $31.82 \pm 5.38$ & 0.95 & $\mathrm{P}>0.05$ \\
\hline MFI total score & $53.92 \pm 11.82$ & $55.03 \pm 12.10$ & 1.26 & $\mathrm{P}>0.05$ \\
\hline \multicolumn{5}{|c|}{ Fatigue symptom dimensions } \\
\hline General fatigue & $13.17 \pm 3.15$ & $13.26 \pm 3.13$ & 0.61 & $\mathrm{P}>0.05$ \\
\hline Physical fatigue & $11.76 \pm 2.96$ & $12.14 \pm 3.14$ & 0.94 & $\mathrm{P}>0.05$ \\
\hline Reduced activity & $11.19 \pm 3.21$ & $11.35 \pm 3.32$ & 0.53 & $\mathrm{P}>0.05$ \\
\hline Mental fatigue & $8.93 \pm 3.52$ & $9.16 \pm 3.43$ & 0.96 & $\mathrm{P}>0.05$ \\
\hline $\begin{array}{l}\text { Reduced } \\
\text { motivation }\end{array}$ & $8.87 \pm 2.14$ & $9.12 \pm 2.25$ & 0.84 & $\mathrm{P}>0.05$ \\
\hline
\end{tabular}

TNF- $\alpha$ : tumor necrosis factor - alpha; IL-6: Interleukin-6; BMI: Body Mass Index; IL-8: Interleukin-8; MFI: Multidimensional Fatigue Inventory.

Moreover, there were significant differences between both groups at the end of the study (table 4).

Table 4: Values of TNF- $\alpha$, IL-6, IL-8, MFI total score and fatigue symptom dimensions in group (A) and group (B) at the end of the study.

\begin{tabular}{|l|c|c|c|c|}
\hline \multirow{2}{*}{} & \multicolumn{2}{|c|}{ Mean + SD } & \multirow{2}{*}{ t- value } & \multirow{2}{*}{ Significance } \\
\cline { 2 - 4 } & Group (A) & Group (B) & 7.15 & $\mathrm{P}<0.05$ \\
\hline TNF-a $(\mathrm{pg} / \mathrm{mL})$ & $4.37 \pm 1.48^{*}$ & $6.11 \pm 1.42$ & 5.91 & $\mathrm{P}<0.05$ \\
\hline IL-6 $(\mathrm{pg} / \mathrm{mL})$ & $5.04 \pm 1.92^{*}$ & $6.57 \pm 2.18$ & 5.91 & $\mathrm{P}<0.05$ \\
\hline IL-8 $(\mathrm{pg} / \mathrm{mL})$ & $12.03 \pm 3.61^{*}$ & $14.25 \pm 3.70$ & 7.71 & $\mathrm{P}<0.05$ \\
\hline BMI $\left(\mathrm{kg} / \mathrm{m}^{2}\right)$ & $26.82 \pm 4.88^{*}$ & $31.42 \pm 5.38$ & 7.23 & $\mathrm{P}<0.05$ \\
\hline MFI total score & $41.11 \pm 13.72^{*}$ & $55.03 \pm 12.10$ & 6.31 & $\mathrm{P}<0.05$ \\
\hline Fatigue symptom dimensions & \multicolumn{3}{|l}{} \\
\hline General fatigue & $9.52 \pm 3.61^{*}$ & $13.26 \pm 3.13$ & 5.16 & $\mathrm{P}<0.05$ \\
\hline Physical fatigue & $8.74 \pm 2.92^{*}$ & $12.14 \pm 3.14$ & 6.42 & $\mathrm{P}<0.05$ \\
\hline $\begin{array}{l}\text { Reduced } \\
\text { activity }\end{array}$ & $8.15 \pm 3.43^{*}$ & $11.35 \pm 3.32$ & 5.38 & $\mathrm{P}<0.05$ \\
\hline Mental fatigue & $7.54 \pm 3.24^{*}$ & $9.16 \pm 3.43$ & 6.53 & \\
\hline $\begin{array}{l}\text { Reduced } \\
\text { motivation }\end{array}$ & $7.16 \pm 3.41^{*}$ & $9.12 \pm 2.25$ & 5.17 & \\
\hline
\end{tabular}

TNF- $\alpha$ : tumor necrosis factor - alpha; IL-6: Interleukin-6; BMI: Body Mass Index; IL-8: Interleukin-8;

MFI: Multidimensional Fatigue Inventory; $\left(^{*}\right)$ indicates a significant difference between the two groups, $\mathrm{P}<0.05$.

\section{Discussion}

Diabetes mellitus is a major public health problem that affects approximately $6 \%$ of the world's adult population $^{23}$. Fatigue represents a common complaint of patients with diabetes as it can be reported in up to $60 \%$ of patients ${ }^{24}$. This symptom not only impacts the patient's quality of life and compliance to treatment, but it is also associated with an increased risk of diabetic complications ${ }^{25}$. Significant associations were found between fatigue symptom dimensions and circulating levels of inflammatory markers in obese patients with type 2 diabetes, suggesting the involvement of inflammatory processes in the development of type 2 diabetes-related fatigue ${ }^{26}$. 
To our knowledge, this is the first study addressing fatigue symptoms associated with markers of systemic inflammation parameters of obese patients with type 2 diabetes after 12 weeks of concurrent training. We observed reduction of markers of systemic inflammation and fatigue symptoms. The results of our study agreed with several previous studies suggesting 12-weeks aerobic exercise training program promotes the modulation of systemic inflammation and fatigue symptoms of obese patients with type 2 diabetes ${ }^{27-39}$.

Rosety-Rodriguez and colleagues conducted a 12-week arm cranking exercise program for spinal cord injury patients at a moderate work intensity of $50 \%$ to $65 \%$ of heart rate reserve for of 3 sessions per week. Their results proved that arm cranking exercise improved lowgrade systemic inflammation by decreasing plasma levels of inflammatory cytokines ${ }^{28}$. Trøseid and colleagues stated that 12 weeks exercise training program reduces plasma levels of chemo-attractant protein-1 (MCP-1) and interleukin-8 (IL-8) in subjects with the metabolic syndrome ${ }^{29}$. Valentine and colleagues conducted a study on one hundred eighty-two community-dwelling older adults and their results proved that increasing physical activity levels had important implications for reducing their levels of fatigue and markers of systemic inflammation $^{30}$.

Learmonth and colleagues conducted a pilot study to determine whether a 15-minute bout of moderate-intensity aerobic cycling exercise would affect symptoms (pain and fatigue) and function (Timed 25-Foot Walk test and Timed Up and Go test) in people with multiple sclerosis (MS) or chronic fatigue syndrome (CFS), their results suggest that people with MS or CFS may undertake 15 minutes of cycling as moderate aerobic exercise with no expected negative impact on pain, fatigue or function $^{31}$. Sangelaji and colleagues conducted a randomized controlled clinical trial on 59 multiple sclerosis patients who received 10 weeks of combination therapy including aerobic, strengthening, balancing and stretching exercises. Exercise had significant effect on improving balance, fatigue and quality of life in multiple sclerosis patients ${ }^{32}$. Maniam and colleagues conducted an exercise program for hemodialysis patients, three times a week for 12 weeks and concluded that low-to-moderate-intensity exercise is effective for improving fatigue, sleep disorders and the overall quality of life among hemodialysis patients ${ }^{33}$.

Smith and colleagues conducted a study on sixty sub- jects who completed a 12-week supervised exercise program and concluded that supervised aerobic exercise training safely decreases fatigue, weight, BMI, subcutaneous fat and abdominal girth (central fat) in HIV-1infected individuals ${ }^{34}$. Yang and colleagues proved that a mild to moderate-intensity aerobic exercise program for six weeks reduces the fatigue of Taiwanese women with breast cancer undergoing radiotherapy ${ }^{35}$. Durcan and colleagues conducted a 12-week exercise training program on forty rheumatoid arthritis patients. They concluded that exercise program resulted in significant improvement in sleep quality and fatigue ${ }^{36}$. Taso and colleagues proved that an eight week yoga exercise program developed in this study effectively reduced fatigue in 60 patients with breast cancer but did not reduce depression or anxiety ${ }^{37}$.

The physiological mechanisms underlying these effects were not elucidated; however, both cancer and type 2 diabetes are associated with higher levels of inflammatory cytokines and exercise may have anti-inflammatory properties $^{38,39}$.

The new finding in our study is that a program of aerobic exercise training with an intensity $60-70 \%$ of maximum heart rate for three months can improve symptoms of fatigue related to inflammatory cytokines in obese patients with type 2 diabetes.

\section{Conclusion}

The current study proved that treadmill walking exercise training is an effective treatment policy to improve symptoms of fatigue related to inflammatory cytokines in obese patients with type 2 diabetes.

\section{Acknowledgment}

This project was funded by the Deanship of Scientific Research (DSR), King Abdulaziz University, Jeddah, under grant no. (25-142-1436-G). The authors, therefore, acknowledge with thanks DSR technical and financial support.

\section{References}

1. Fritschi C, Quinn L, Hacker E. Fatigue in women with type 2 diabetes, Diabetes Educ 2012;38(5):662 PubMed -72 .

2. Fritschi C. and Quinn L. Fatigue in patients with diabetes: a review. J Psychosom Res 2010; 69: 33- PubMed ;41.

3. Lasselin J, Layé S, Dexpert S, Aubert A, Gonzalez C, Gin H, Capuron H. Fatigue symptoms relate to system- 
ic inflammation in patients with type 2 diabetes. Brain, Behavior, and Immunity 2012; 26(8): 1211 PubMed -1219. 4. American Diabetes Association. Diagnosis and classification of diabetes mellitus. Diabetes Care 2008; 31 Suppl 1:S55-60.

5. Pickup J. Inflammation and activated innate immunity in the pathogenesis of type 2 diabetes. Diabetes Care 2004; 27(3):813 PubMed -23. 2004 Mar.

6. Hlatky M, Chung S, Escobedo J. The effect of obesity on quality of life in patients with diabetes and coronary artery disease, Am Heart J 2010;159(2):292 PubMed -300 .

7. Alexandraki K, Piperi C, Ziakas P, Apostolopoulos N, Makrilakis K, Syriou V, Diamanti-Kandarakis E, Kaltsas $G$, Kalofoutis A. Cytokine secretion in long-standing diabetes mellitus type 1 and 2: associations with low-grade systemic inflammation. J Clin. Immunol 2008; 28: 314- PubMed ;321.

8. Pham M, Hawa M, Pfleger C, Roden M, Schernthaner G, Pozzilli P, Buzzetti R, Scherbaum W, Seissler J, Kolb H, Hunter S, Leslie R, Schloot N. Pro- and anti-inflammatory cytokines in latent autoimmune diabetes in adults, type 1 and type 2 diabetes patients: action LADA 4. Diabetologia 2011;54: 1630- PubMed ;1638.

9. Cavelti-Weder C, Furrer R, Keller C, Babians-Brunner A, Solinger A, Gast H, Fontana A, Donath M, Penner I. Inhibition of IL-1beta improves fatigue in type 2 diabetes. Diabetes Care 2011; 34:e158.

10. Capuron L, Miller A. Immune system to brain signaling: neuropsychopharmacological implications. Pharmacol Ther 2011; 130 :226- PubMed ;238.

11. Mraz M, Lacinova Z, Drapalova J, Haluzikova D, Horinek A, Matoulek M, Trachta P, Kavalkova P, Svacina S, Haluzik M. The effect of very-lowcalorie diet on mRNA expression of inflammation-related genes in subcutaneous adipose tissue and peripheral monocytes of obese patients with type 2 diabetes mellitus. J Clin Endocrinol Metab 2011; 96: E606-E613.

12. Sam S, Haffner S, Davidson M, D’Agostino S , Feinstein S, Kondos G, Perez A, Mazzone T. Relation of abdominal fat depots to systemic markers of inflammation in type 2 diabetes. Diabetes Care 2009; 32: 932 PubMed ;937.

13. Su S, Pei D, Hsieh C, Hsiao F, Wu C, Hung Y. Circulating pro-inflammatory cytokines and adiponectin in young men with type 2 diabetes. Acta Diabetol 2011; 48 : 113- PubMed ;119.

14. Pham M, Hawa M, Pfleger C, Roden M, Schernthaner G, Pozzilli P, Buzzetti R, Scherbaum W, Seissler J, Kolb H, Hunter S, Leslie R, Schloot N. Pro- and anti-in- flammatory cytokines in latent autoimmune diabetes in adults, type 1 and type 2 diabetes patients: action LADA 4. Diabetologia 2011; 54: 1630- PubMed ;1638.

15. Stewart K. Role of exercise training on cardiovascular disease in persons who have type 2 diabetes and hypertension. Cradiol Clin 2004; 22(4):569 PubMed -86. 16. Thomas N, Alder E, Leese G. Barriers to physical activity in patients with diabetes, Postgrad Med J 2004;80(943):287 PubMed -91.

17. Vieira V, Hu L, Valentine R, McAuley E, Evans E, Baynard T, Woods J. Reduction in trunk fat predicts cardiovascular exercise training-related reductions in C-reactive protein. Brain Behav Immun 2009; 23: 485PubMed ;491.

18. Puetz T, Flowers S, O'Connor P. A randomized controlled trial of the effect of aerobic exercise training on feelings of energy and fatigue in sedentary young adults with persistent fatigue. Psychother Psychosom 2008; $77: 167-174$.

19. Puetz T. Physical activity and feelings of energy and fatigue: Epidemiological evidence. Sports Med 2006; 36(9):767 PubMed -780.

20. O'Connor P, Puetz T. Chronic physical activity and feelings of energy and fatigue. Med Sci Sports Exerc 2005; 37(2):299-305.

21.Smets E, Garssen B, Bonke B, Haes J. The Multidimensional Fatigue Inventory (MFI); psychometric qualities of an instrument to assess fatigue. J. Psychosom Res 1995 ; 39: 315- PubMed ;325.

22. American College of Sports Medicine .Guidelines for graded exercise testing and exercise prescription, Lea \& Febiger, Philadelphia, 2005.

23. American Diabetes Association. Economic costs of diabetes in the U.S. in 2007. Diabetes Care 2008; 31:596PubMed ;615.

24. Fritschi C, Quinn L. Fatigue in Patients with Diabetes: A Review. J Psychosom Res 2010; 69(1): 33 PubMed $-41$.

25.Stewart S, Woodward R, Rosen A, Cutler D. The impact of symptoms and impairments on overall health in US national health data. Med Care 2008; 46(9):954 PubMed -962.

26.Lasselin J, Layé S, Dexpert S, Aubert A, Gonzalez C, Gin H, Capuron L. Fatigue symptoms relate to systemic inflammation in patients with type 2 diabetes. Brain Behav Immun 2012; 26(8):1211 PubMed -9.

27. McMillan E, Newhouse I, Exercise is an effective treatment modality for reducing cancer-related fatigue and improving physical capacity in cancer patients and survivors: A meta-analysis, Appl Physiol Nutr Metab 2011; 36(6):892-903. 
28. Rosety-Rodriguez M, Camacho A, Rosety I, Fornieles G, Rosety M, Diaz A, Bernardi M, Rosety M, Ordonez F. Low-grade systemic inflammation and leptin levels were improved by arm cranking exercise in adults with chronic spinal cord injury. Arch Phys Med Rehabil 2014 ; 95(2):297-302.

29. Trøseid M, Lappegård K, Claudi T, Damås J, Mørkrid L, Brendberg R, Mollnes T. Exercise reduces plasma levels of the chemokines MCP-1 and IL- 8 in subjects with the metabolic syndrome. Eur Heart J 2004; 25(4):349 PubMed -55.

30. Valentine R, Woods J, McAuley E, Dantzer R, Evans $\mathrm{E}$. The associations of adiposity, physical activity and inflammation with fatigue in older adults. Brain Behav Immun 2011; 25(7):1482 PubMed -90.

31. Learmonth Y, Paul L, McFadyen A, Marshall-McKenna R, Mattison P, Miller L, McFarlane N. Short-term effect of aerobic exercise on symptoms in multiple sclerosis and chronic fatigue syndrome: a pilot study. Int J MS Care 2014 summer; 16(2):76-82.

32. Sangelaji B, Nabavi S, Estebsari F, Banshi MR, Rashidian H, Jamshidi E, Dastoorpour M. Effect of combination exercise therapy on walking distance, postural balance, fatigue and quality of life in multiple sclerosis patients: a clinical trial study. Iran Red Crescent Med J 2014;16(6):e17173.

33. Maniam R, Subramanian P, Singh S, Lim S, Chinna

K, Rosli R. Preliminary study of an exercise programme for reducing fatigue and improving sleep among longterm haemodialysis patients. Singapore Med J 2014; 55(9):476 PubMed -82.

34. Smith B, Neidig J, Nickel J, Mitchell G, Para M, Fass R. Aerobic exercise: effects on parameters related to fatigue, dyspnea, weight and body composition in HIV-infected adults. AIDS 2001; 15(6):693 PubMed $-701$.

35. Yang T, Chen M, Li C. Effects of an aerobic exercise programme on fatigue for patients with breast cancer undergoing radiotherapy. J Clin Nurs. 2015;24(1-2 PubMed ):202-11.

36. Durcan L, Wilson F, Cunnane G. The effect of exercise on sleep and fatigue in rheumatoid arthritis: a randomized controlled study. J Rheumatol 2014 ; 41(10):1966 PubMed -73 .

37. Taso C, Lin H, Lin W, Chen S, Huang W, Chen S. The effect of yoga exercise on improving depression, anxiety, and fatigue in women with breast cancer: a randomized controlled trial. J Nurs Res 2014; 22(3):155 PubMed -64 .

38. Pedersen B. Exercise-induced myokines and their role in chronic diseases, Brain Behav Immun 2011; 25(5):811 PubMed -6.

39. Petersen A, Pedersen B. The role of IL-6 in mediating the anti-inflammatory effects of exercise, J Physiol Pharmacol 2006; 57(Suppl. 10):43-51. 